\title{
Research on the Sapphire Auction Market in China Based on Data Analysis
}

ZHOU Qishen,JI Chengyu,XIE Meng, WU Xiaoying,ZHAO Yue

Gemological Institute, China University of Geosciences, Wuhan, China

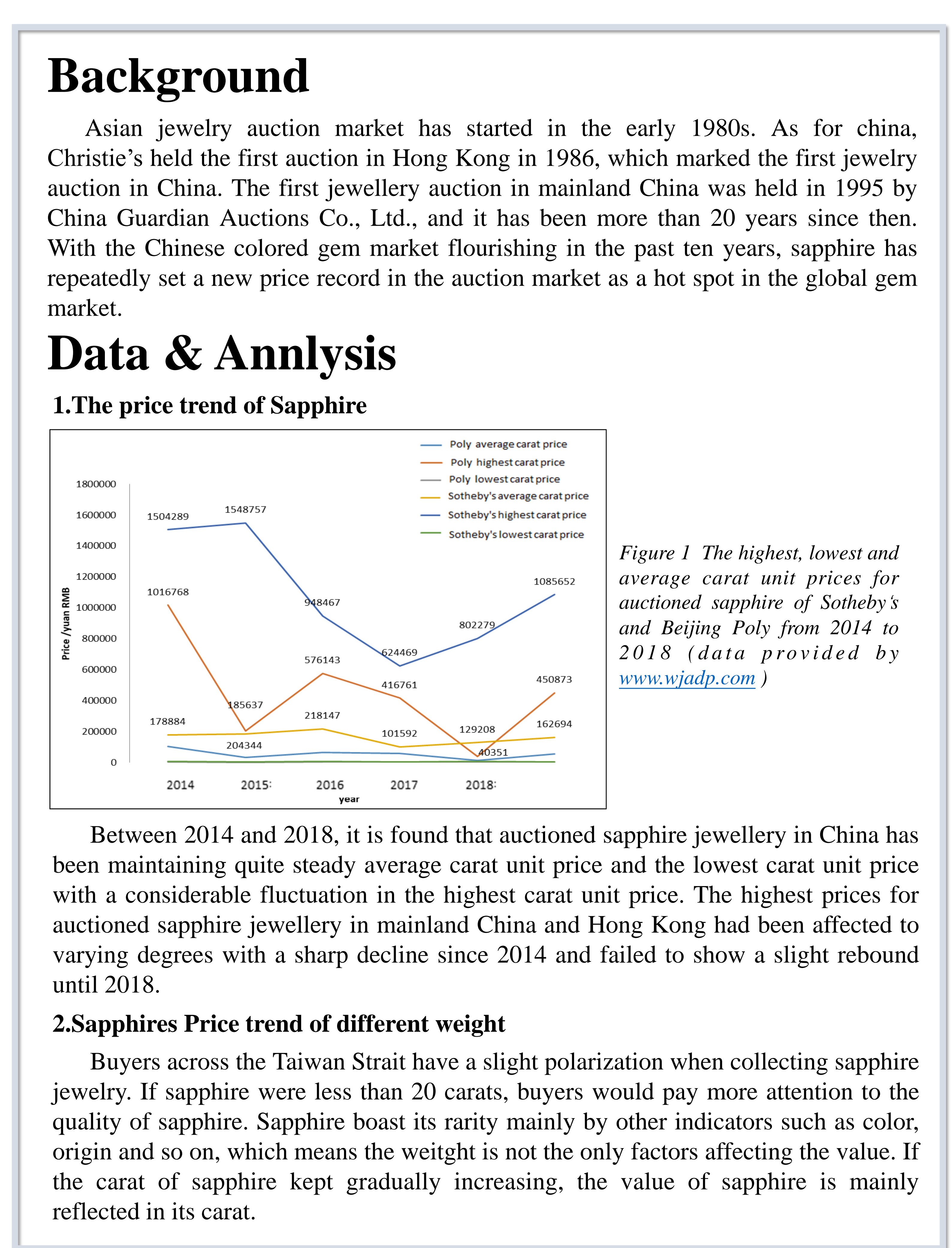

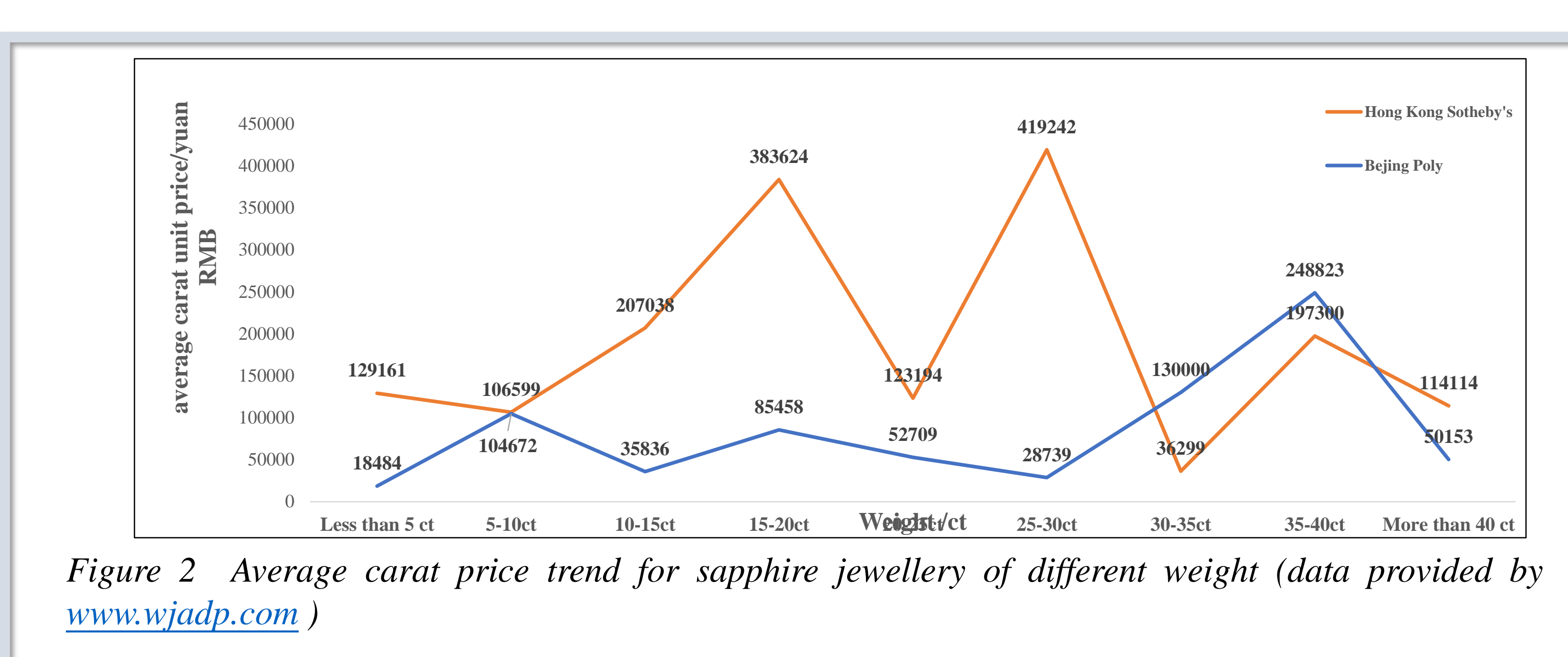

3.Statistical analysis of the origin of high-end sapphire

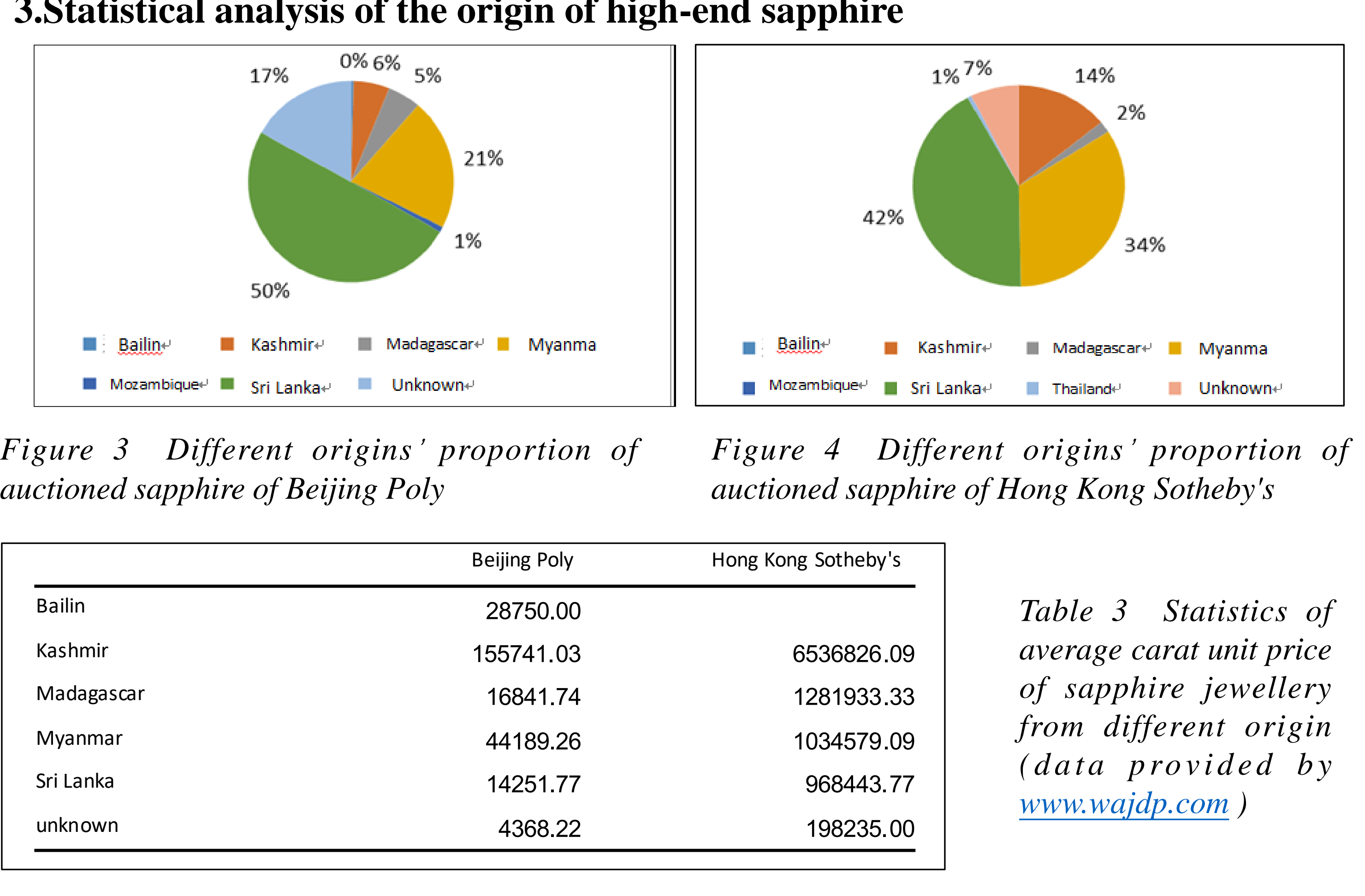

Sapphire auction market in Hong Kong has a slightly higher demand for sapphire's origin, mainly reflected in the fact that the number of auctioned sapphire of, for example, Kashmir and Burma is more than that of the mainland China. The
difference between the auction market of sapphire jewelry in Hong Kong and mainland difference between the auction market of sapphire jewelry in Hong Kong and mainland
is mainly reflected in the fact that the value of sapphire of Myanmar auctioned in mainland China is pretty high, while the value of sapphire of Madagascar, Myanmar sapphire auction market in Hong Kong relies on more mature buyers of colored gemstone within the more mature quality evaluation system of sapphire, which requires a comprehensive purchasing decision based on the assessment of multiple indicators instead of blindly pursuing the sapphire carat, origin, color and other

4tatistical analysis of the color of high-end sapphire

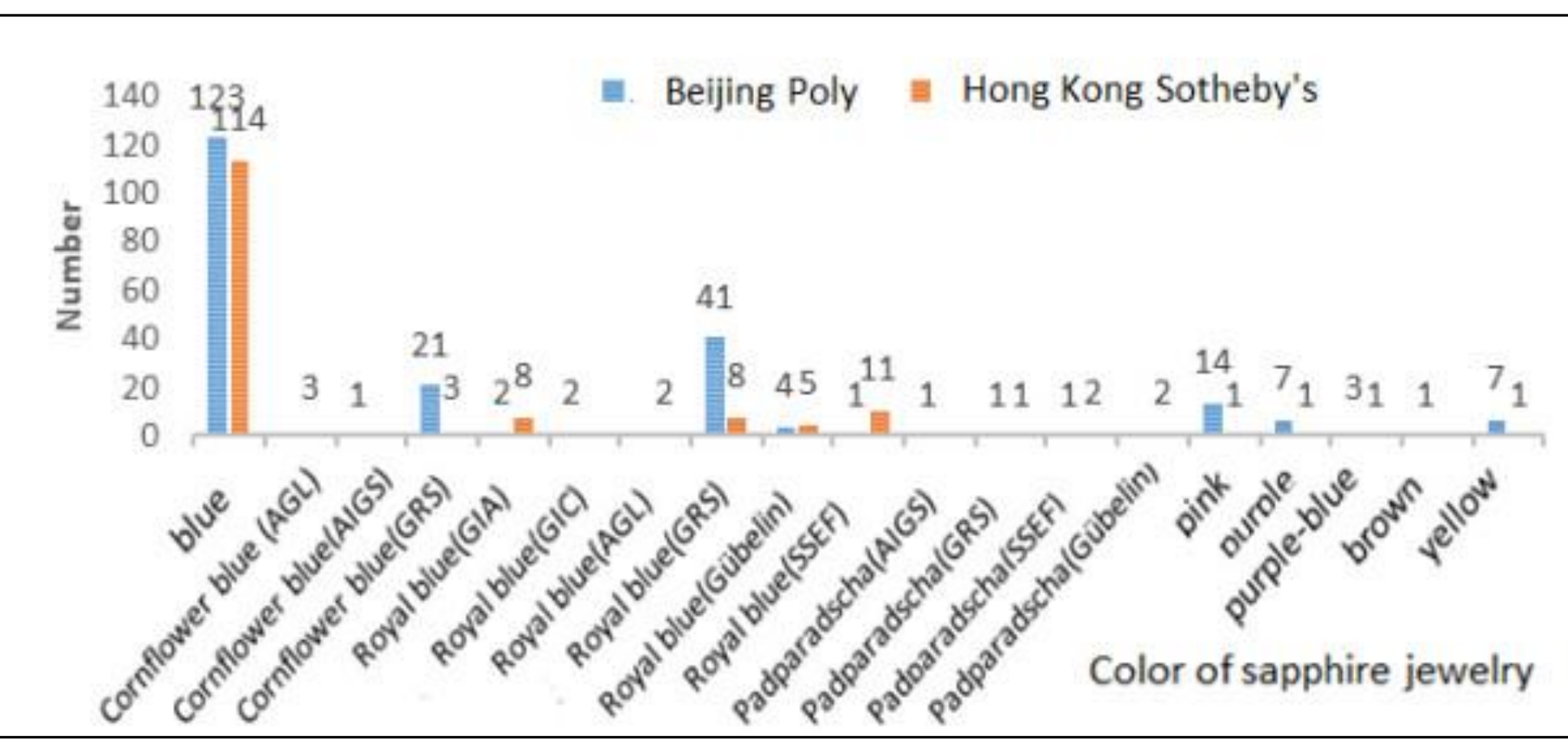

Figure 5 Distribution of auctioned sapphire in different colors in
China (data provided by wwww widplpcom)

llue sapphires are the most popular in the sapphire market, while sapphire of other colors, such as pink, purple, brown, and yellow, are less common. Colors that can affect the value of sapphire jewelry with a high commercial value, such as "Bluebonnet Blue", "Royal Blue", "Paparaccia", account for a relatively high proportion. Third-party accreditation bodies

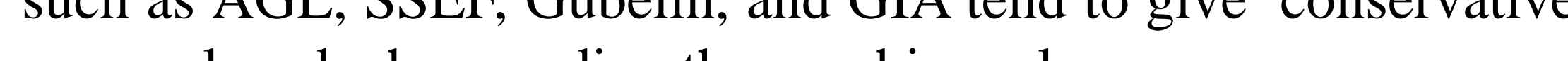
5.0

5.Other factors affecting the market price of high-end sapphire

cof

Conclusion \& Discussion

Form the micro perspective, consumers' demands for sapphire jewelry mainly centered upon three aspects: weight, place of the price of Kashmir's sapphires is obviously rising with the highest average carat unit price, but the market demends the most sapphires produced in Burma and Sri Lanka with pretty high average carat unit price. Madagascar sapphire of highquality is a newcomer to the market, whose value is immune to the effect of origin. Third, the impact of color on the value of sapphire is more significant. Hong Kong has higher requirements for color grades issued by third-party accreditation bodies than mainland China.

From the macro perspective, it was found that the market's demand for sapphire jewellery did not reduce because of

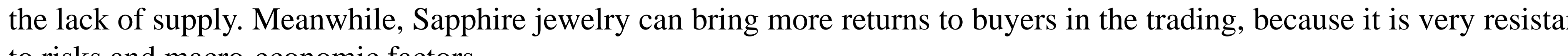
References 